\title{
Validation of the estimated glomerular filtration rate equation for Japanese children younger than 2 years
}

\author{
Yoshimitsu Gotoh $^{1}$ (D) Osamu Uemura ${ }^{2} \cdot$ Naoya Fujita $^{3} \cdot$ Yuko Hamasaki $^{4} \cdot$ Masataka Honda $^{5} \cdot$ Kenji Ishikura $^{6} \cdot$ On \\ behalf of the Pediatric CKD Study Group in Japan in conjunction with the Committee of Measures for Pediatric CKD \\ of the Japanese Society of Pediatric Nephrology
}

Received: 16 July 2021 / Accepted: 19 November 2021 / Published online: 1 January 2022

(c) The Author(s) 2021

\begin{abstract}
Background We have developed a simple and easy method of estimating the glomerular filtration rate (eGFR) of serum creatinine in Japanese children (eGFR $\mathrm{Uemura}$ ). The eGFR equation is for children aged 2-18 years. Therefore Uemura et al. developed an equation for children younger than 2 years $\left(\mathrm{eGFR}_{\mathrm{under} 2}\right)$. The aim of the present study was to validate this new equation.

Methods We collected the data of 13 patients from previous studies and compared the results of eGFR under $2_{2}$ eGFR Uemura $_{\text {, }}$

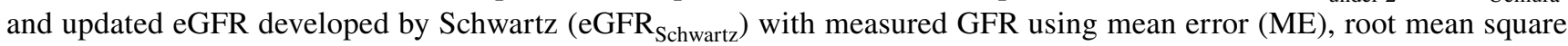
error (RMSE), $P_{30}$ and Bland-Altman analysis.

Results The ME of eGFR ${ }_{\text {under } 2}, \mathrm{eGFR}_{\text {Uemura }}$ and eGFR $\mathrm{Cchwartz}_{\text {were }} .3 \pm 15.9,7.7 \pm 14.5$, and $16.0 \pm 18.2 \mathrm{ml} / \mathrm{min} / 1.73 \mathrm{~m}^{2}$, respectively. The RMSEs were 15.5, 15.9, and 49.6, respectively. The $P_{30}$ values were $76.9 \%, 76.9 \%$, and $53.8 \%$, respectively. The graph of Bland-Altman bias analysis showed fan-shape. The eGFR under $2_{2}$ equation was the most accurate in the three equations.
\end{abstract}

Conclusion The eGFR $\mathrm{under}_{2}$ equation was useful for Japanese children younger than 2 years.

Keywords Validation $\cdot$ Estimated glomerular filtration rate $\cdot$ Children under 2 years of age $\cdot$ Japanese

Yoshimitsu Gotoh

ygotoh@nagoya2.jrc.or.jp

1 Department of Pediatric Nephrology, Japanese Red Cross Aichi Medical Center Nagoya Daini Hospital, 2-9 Myoken-cho Showa-ku, Nagoya-shi, Aichi 466-8650, Japan

2 Department of Pediatrics, Ichinomiya Medical Treatment and Habilitation Center, 1679-2 Tomida-nagaresuji, Ichinomiya-shi, Aichi 494-0018, Japan

3 Department of Pediatric Nephrology, Aichi Children's Health and Medical Center, 7-426 Morioka-cho, Obu-shi, Aichi 474-8710, Japan

4 Department of Nephrology, Toho University Faculty of Medicine, 6-11-1 Oomori Nishi Ota-ku, Tokyo 143-8541, Japan

5 Department of Nephrology, Tokyo Metropolitan Children's Medical Center, 2-8-29 Musasidai, Futyu-shi, Tokyo 183-8561, Japan

6 Department of Pediatrics, Kitasato University Hospital, 1-15-1 Kitasato Minami-ku, Sagamihara-shi, Kanagawa 252-0375, Japan

\section{Introduction}

The gold standard for evaluation of renal function is inulin clearance (Cin). However, the procedure of Cin is complicated and difficult, especially in younger children and/ or patients with bladder dysfunction. Therefore, various simple and easy methods to determine the estimated GFR (eGFR) have been developed. Recently, the most known equation for eGFR used in children is the updated Schwartz $\left(\mathrm{eGFR}_{\text {Schwartz }}\right)$ equation [1]. However, Uemura et al. reported

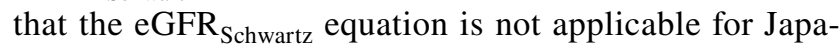
nese children [2]. Therefore, an original equation for eGFR $\left(\mathrm{eGFR}_{\text {Uemura }}\right.$ ) was developed using serum creatinine $(\mathrm{Cr})$ in Japanese children [3], and its accuracy was validated [4]. However, the equation was for children aged 2-18 years. Therefore, an equation for children younger than 2 years was then developed by multiplying eGFR $_{\text {Uemura }}$ by a coefficient $(0.107 \times \ln ($ age[month] $)+0.656)$ [5]. In this study, we aimed to validate $\mathrm{eGFR}_{\text {under } 2}$ equation. 


\section{Material and methods}

\section{Study population}

We extracted the data of patients under 2 years of age from three studies. The first was 7 of 174 patients' data when

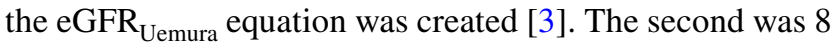
of 140 patients' data when the accuracy of the eGFR Uemura equation was validated [4]. The third was 1 of 59 patients' data validated the safety of Inulide ${ }^{\circledR}$ for Japanese children (in press) (Table 1). All data were collected from pediatric patients with chronic kidney disease (CKD) in clinical need of Cin. Finally, we used data from 13 patients after excluding patients (Table1).

The measured GFR (mGFR) for each patient was obtained using Cin. The procedure is described in a previous report [6]. Cin values were measured in the same way in three studies.

The calculate method of eGFR $\mathrm{under}_{2}$ is as follows:

1. The reference serum $\mathrm{Cr}$ level ( $\mathrm{ref} \mathrm{Cr}$ ) is shown by the following two equations of body length $(x)$ : males: ref $\mathrm{Cr}=-1.259 \mathrm{x}^{5}+7.815 x^{4}-18.57 x^{3}+$ $21.39 x^{2}-11.71 x+2.628$ females: ref $\mathrm{Cr}=-4.536 x^{5}+27.16 x^{4}-63.47 x^{3}+$ $72.43 x^{2}-40.06 x+8.778$

2. Provisional $\mathrm{GFR}=110.2 \times(\mathrm{ref} \mathrm{Cr} /$ patient's serum $\mathrm{Cr})+2.93$

3. $R=0.107 \times \ln [$ age (months) $]+0.656$

Table 1 Characteristics of the 13 patients included in this study

\begin{tabular}{|c|c|c|}
\hline Characteristics & Median (IQR) & $n$ \\
\hline Age (months) & $17.0(10.0-20.5)$ & \\
\hline \multicolumn{3}{|l|}{ Gender } \\
\hline Male & & 11 \\
\hline Female & & 2 \\
\hline \multicolumn{3}{|l|}{ CKD stage } \\
\hline Stage 1 & & 2 \\
\hline Stage 2 & & 4 \\
\hline Stage 3 & & 6 \\
\hline Stage 4 & & 1 \\
\hline \multicolumn{3}{|l|}{ Renal abnormality } \\
\hline $\begin{array}{l}\text { Congenital anomalies of the } \\
\text { kidney and urinary tract }\end{array}$ & & 6 \\
\hline Solitary kidney & & 3 \\
\hline Reflux nephropathy & & 2 \\
\hline Hydronephrosis & & 1 \\
\hline Small kidney & & 1 \\
\hline
\end{tabular}

$C K D$ chronic kidney disease, $I Q R$ interquartile range
4. eGFR under 2 years of age $\left(\mathrm{eGFR}_{\text {under } 2}\right)=R \times$ provisional GFR

\section{Exclusion criteria and cases excluded}

The exclusion criteria were as follows:

1. Primary diseases including severe obstructive uropathy, infection during treatment, inflammatory disease, dehydration, neuromuscular disease, severe cardiac, hepatic, or pancreatic disease, and/or endocrine disease, including thyroid impairment.

2. Cases in which the ratios of inulin excretion and intravenous inulin administration were $<0.5$, or $>1.5$, during the measurement of Cin. We determined the dose of intravenous inulin by assuming that the blood concentration was constant during testing. Ratios of inulin excretion and intravenous inulin that were not within 0.5 and 1.5 may have been due to failure to collect all urine.

3. Cases in which the measured GFR (mGFR) was $>150 \mathrm{ml} / \mathrm{min} / 1.73 \mathrm{~m}^{2}$; pediatric patients with CKD due to a hyperfiltration disease such as diabetic nephropathy are rare. We were only interested in cases in which GFR was $<120 \mathrm{ml} / \mathrm{min} / 1.73 \mathrm{~m}^{2}$. Therefore, we excluded cases in which $\mathrm{mGFR}$ was $>150 \mathrm{ml} / \mathrm{min} / 1.73 \mathrm{~m}^{2}$.

\section{Statistical analysis}

To validate eGFR under 2 equation, we used four methods as follows:

1. Mean error (ME): to evaluate the mean difference between each value for eGFR and mGFR values

2. Root mean square error (RMSE): to evaluate the precision of eGFR and mGFR values.

3. $P_{30}$ (the percentage of eGFR value within $30 \%$ of mGFR): to evaluate the accuracy of eGFR and mGFR values.

4. Bland-Altman analysis (difference versus average): to determine agreement with the estimation.

We also compared these statistical results of eGFR $\mathrm{Gnder}_{2}$ equations, with the results of eGFR $\mathrm{Uemura}_{\text {, }}$, and eGFR $\mathrm{Schwartz}_{\text {. }}$

The formula for eGFR Uemura equation is mentioned above in the calculation method of eGFR $\mathrm{under}_{2}$ from (1) to (2). First, calculate the reference $\mathrm{Cr}$ level as described (1), and then the $\mathrm{eGFR}_{\text {Uemura }}$ from reference $\mathrm{Cr}$ and patient's serum $\mathrm{Cr}$ using the method described in (2).

The updated Schwartz equation is as follows: eGFR $(\mathrm{ml} /$ $\left.\min / 1.73 \mathrm{~m}^{2}\right)=0.413 \times$ body length $(\mathrm{cm}) /$ serum $\mathrm{Cr}$ value $(\mathrm{mg} / \mathrm{dL})$ by enzymatic $\mathrm{Cr}$ determination in children aged 1-16 years [1]. Therefore, in the second analysis, the data of three patients under 1 year of age were excluded. Finally, 
data from 10 patients were used for comparison between $\mathrm{eGFR}_{\text {under } 2}$ and eGFR $\mathrm{Schwartz}_{\text {. }}$

All analyses were performed using GraphPad Prism for Mac OS X (version 7.0).

\section{Results}

\section{Characteristics of the study population (Table 1)}

Data of 6 patients were extracted from the three studies. Data of three patients were excluded because the ratios of urinary inulin excretion to intravenous inulin administration

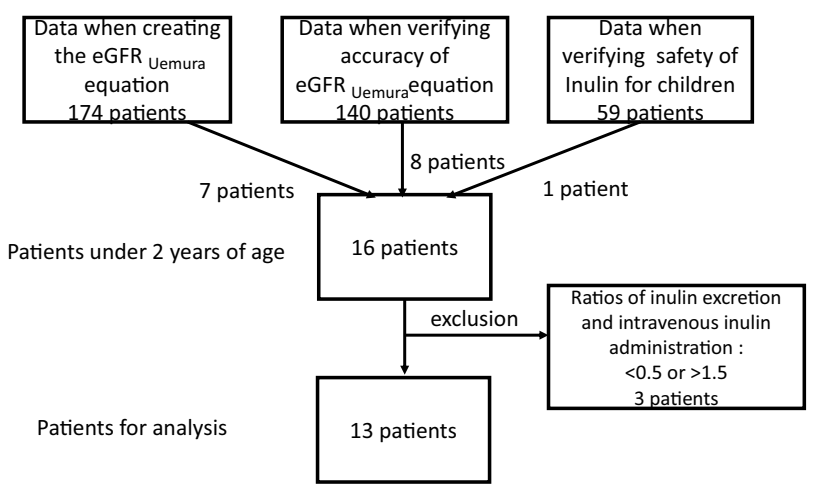

Fig. 1 Flow chart of included data were $<0.5$ or $>1.5$. None of the patients were included in the 1 or 3 exclusion criteria. Finally, 13 patients' data (2 female, median 17.0 months of age [interquartile range (IQR) 10.0-20.5 months, range 1-23 months]) were used for analysis (Fig. 1). The number of chronic kidney disease (CKD) stages 1, 2, 3, 4, and 5 were 2, 4, 6, 1, and 0 , respectively. The number of renal abnormalities, congenital anomalies of the kidney and urinary tract (CAKUT), solitary kidney, reflux nephropathy, hydronephrosis, and small kidney were $6,3,2,1$, and 1 , respectively.

\section{Result of statistical analysis}

Figure 2 shows a scatter plot of mGFR versus each of the three eGFR equations. The straight line shows the equivalent values of mGFR and eGFR. The open circles represent the patient data under 1 year of age. The scatter plots of $\mathrm{eGFR}_{\text {under } 2}$ and eGFR $\mathrm{U}_{\text {Uemura }}$ seem to be similar. Figure 3 shows the Bland-Altman plot of the difference versus the average for both mGFR and each 3 eGFR equations.

Table 2 a shows the numerical values for each examination in all 13 patients. The ME values for $\mathrm{eGFR}_{\text {under } 2}$,

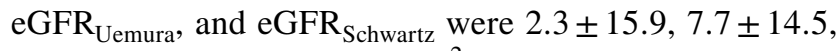
and $16.0 \pm 18.2 \mathrm{ml} / \mathrm{min} / 1.73 \mathrm{~m}^{2}$, respectively. The RMSE values were $15.5,15.9$, and $49.6 \mathrm{ml} / \mathrm{min} / 1.73 \mathrm{~m}^{2}$, respectively. The $P_{30}$ values were $76.9 \%, 76.9 \%$, and $53.8 \%$, respectively. Table $2 \mathrm{~b}$ shows the numerical values for the results of eGFR under $2_{2}$ and eGFR Schwartz $_{\text {in } 10}$ patients aged
Fig. 2 Scatter plot of mGFR versus each 3 eGFR equations. a eGFR under $2_{\text {, b eGFR }}$ Uemura, c eGFR Schwartz. Straight line: $Y=X$, Open circle: data of children under 1-year-old
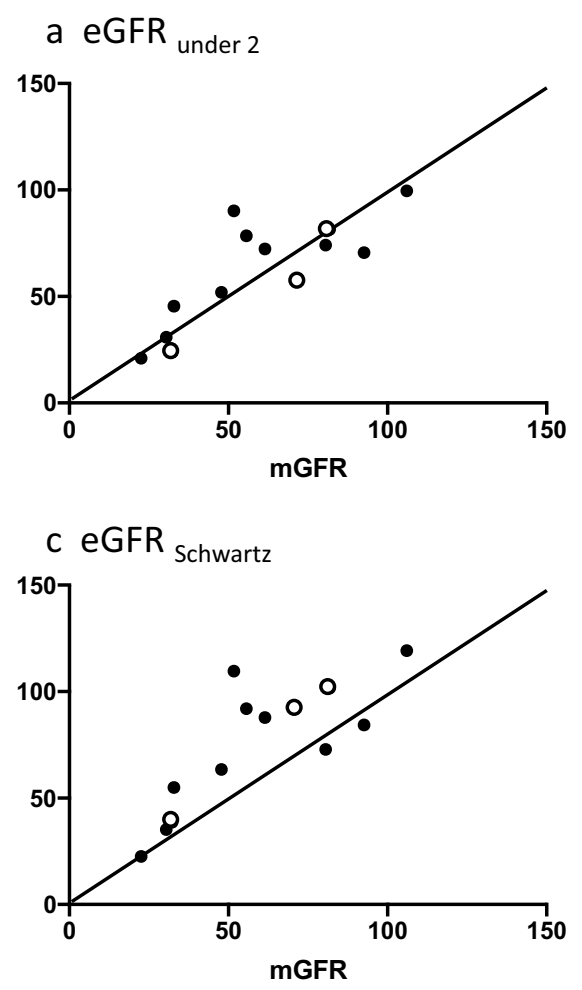

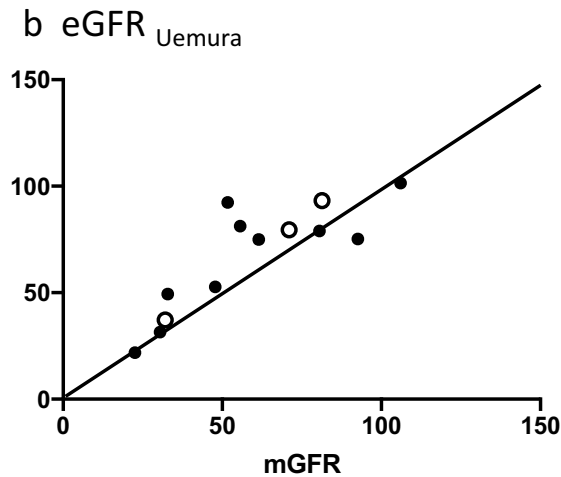

Straight line: $\mathrm{Y}=\mathrm{X}$

Open circle: under 1 year old 
Fig. 3 Bland-Altman plot. Difference versus average mGFR and each 3 eGFR equations. a $\mathrm{eGFR}_{\text {under 2 }}, \mathbf{b}$ eGFR $\mathrm{Uemura}_{\text {, }}, \mathbf{c}$ eGFR $_{\text {Schwartz }}$ Open circle: data of children under 1 year old a eGFR under 2

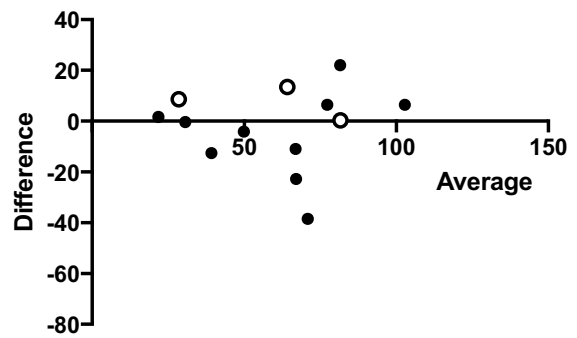

c eGFR ${ }_{\text {schwartz }}$

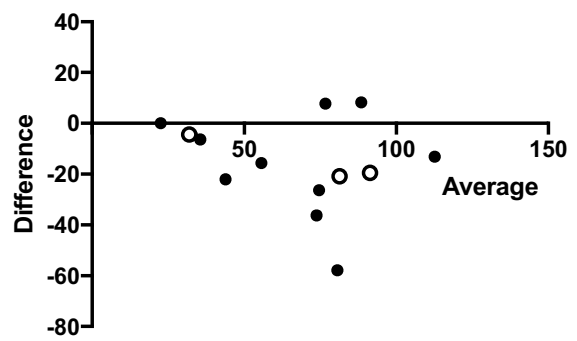

b eGFR Uemura

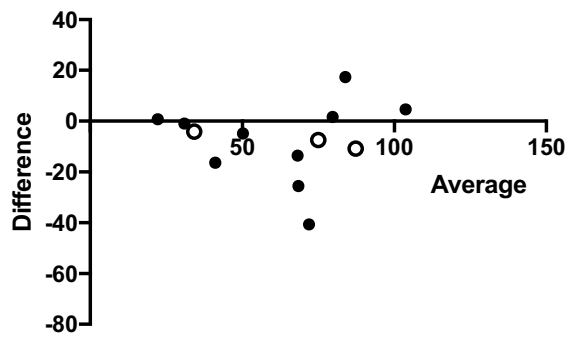

Open circle: under 1 year old

Table 2 Comparison of performance using three eGFR equations, eGFR under $2_{2}$ equation, eGFR Uemura $_{\text {equation and eGFR }}$ Schwartz

(a) Comparison of results with data from 13 patients

\begin{tabular}{|c|c|c|c|}
\hline & $\mathrm{ME}$ (bias) $\left(\mathrm{ml} / \mathrm{min} / 1.73 \mathrm{~m}^{2}\right)(95 \% \mathrm{CI})$ & $\operatorname{RMSE}\left(\mathrm{ml} / \mathrm{min} / 1.73 \mathrm{~m}^{2}\right)$ & $P_{30}(\%)$ \\
\hline $\mathrm{eGFR}_{\text {under2 }}$ & $2.3 \pm 15.9(-7.3$ to 12.0$)$ & 15.5 & 76.9 \\
\hline $\mathrm{eGFR}_{\text {Uemura }}$ & $7.7 \pm 14.5(-1.0$ to 16.5$)$ & 15.9 & 76.9 \\
\hline eGFR $_{\text {Schwartz }}$ & $16.0 \pm 18.2(5.0$ to 27.0$)$ & 49.6 & 53.8 \\
\hline \multicolumn{4}{|c|}{ 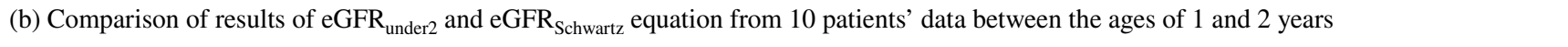 } \\
\hline & $\mathrm{ME}($ bias $)\left(\mathrm{ml} / \mathrm{min} / 1.73 \mathrm{~m}^{2}\right)(95 \% \mathrm{CI})$ & $\operatorname{RMSE}\left(\mathrm{ml} / \mathrm{min} / 1.73 \mathrm{~m}^{2}\right)$ & $P_{30}(\%)$ \\
\hline $\mathrm{eGFR}_{\text {under2 }}$ & $5.3 \pm 17.0(-6.9$ to 17.4$)$ & 16.9 & 70.0 \\
\hline $\mathrm{eGFR}_{\text {Schwartz }}$ & $16.0 \pm 20.7(1.2$ to 30.8$)$ & 50.0 & 50.0 \\
\hline
\end{tabular}

$e G F R$ estimated glomerular filtration rate, $M E$ mean error, $P_{30}$ the percentage of eGFR value within $30 \%$ of measured GFR, $R M S E$ root mean square error

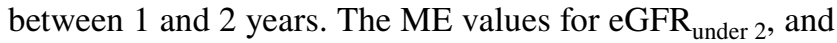
$\mathrm{eGFR}_{\text {Schwartz }}$ were $5.3 \pm 17.0$ and $16.0 \pm 20.7 \mathrm{ml} / \mathrm{min} / 1.73 \mathrm{~m}^{2}$, respectively. The RMSE values were 16.9 and $50.0 \mathrm{ml} /$ $\min / 1.73 \mathrm{~m}^{2}$, respectively. The $P_{30}$ values were $70.0 \%$, and $50.0 \%$, respectively.

Figure 3 shows a scatter plot of the Bland-Altman analysis. In all three equations, the spread of the graph of the Bland-Altman analysis was fan-like shaped, with systematic error.

In the three equations, the values using eGFR under $2_{\text {equa- }}$ tion showed the lowest value for ME and Bland-Altman analysis, and showed the larger values for $\mathrm{P}_{30}$ than that for eGFR $_{\text {Schwartz }}$.

\section{Discussion}

We evaluated a new eGFR equation for children under 2 years of age. Using several statistical techniques, we confirmed that the eGFR $\mathrm{under} 2_{2}$ equation could be useful.

For Japanese children, there are several eGFR equations with surrogate markers, serum $\mathrm{Cr}$ [3], cystatin $\mathrm{C}$ [7], and $\beta 2$ microglobulin [8]. The Cr-based eGFR Uemura equation is the most commonly used method for children aged 2-18 years. Cystatin $\mathrm{C}$ and $\beta 2$ microgrobulin based eGFR are not always available for retrospective epidemiologic studies or common clinical practice. Therefore, we developed 
Cr-based eGFR for children younger than 2 years using

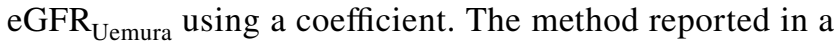
previous article [5] is based on the following idea. Physiologically, kidney function gradually increases from birth and reaches adult stage at the age of 2 years. Using the median normal reference values of GFR for each age (months) up to 2 years examined previously, we estimated the percentage of the normal adult GFR that corresponds to and calculated a regression curve using a logarithmic function. As a result, the coefficient was calculated as $0.107 \times \ln$ [age (months) $]+0.656$. The aim of this study was to evaluate the eGFR under 2 equations. We compared

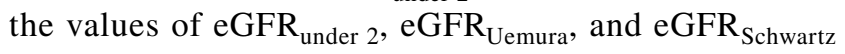
equation using ME, RMSE, $P_{30}$, and Bland-Altman analysis. We divided the patients according to age: 13 patients under 2 years of age and 10 patients aged between 1 and 2 years; patient data underwent two analyses. Because $\mathrm{eGFR}_{\text {under } 2}$ equation is for children under 2 years old, the eGFR $_{\text {Uemura }}$ equation is for children aged 2-18 years and $\mathrm{eGFR}_{\text {Schwartz }}$ is for children aged 1-16 years. Therefore, in the comparison of 10 patients at the age of 1 to 2 years, we only compared eGFR under $2_{2}$ equation and eGFR Schwartz. In the analysis of 13 patients, the ME value of eGFR $\mathrm{under}_{2}$ was the smallest among the three equations. The RMSE value and percent of $P_{30}$ of eGFR $\mathrm{under} 2_{\text {and eGFR }}$ Uemura were similar. On the other hand, the ME and RMSE values of eGFR Schwartz were the highest, and the percentage of $P_{30}$ was the lowest among the three eGFR equations. In the analysis of 10 patients, the ME and RMSE values

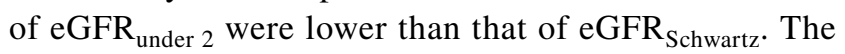
percentage of $\mathrm{P}_{30}$ of eGFR $\mathrm{under}_{2}$ was higher than that of eGFR $_{\text {Schwartz }}$.

This study has several limitations. First, the sampling data was small particular under 1 year of age. Although we collected patients' data from our three previous studies, there were only 13 among 373 patients (3.5\%) under 2 years of age. Further, it is very rare to perform inulin clearance in patients under 2 years of age, thus limiting data collection. In addition to that, there were only two patients of a female under the age of two. However, since there was no gender difference in normal $\mathrm{Cr}$ values at younger ages [9], we believed that this result was not affected. Second, to add to the data as much as possible, we also used the patient data when creating the equation of eGFR $\mathrm{Uemura}_{\text {. }}$ Third, we did not exclude preterm infants and low birth weight infant because we had no information for them. We don't know whether the $\mathrm{GFR}_{\text {under } 2}$ equation can be applied to such cases or not.

\section{Conclusion}

We evaluated the eGFR $\mathrm{under}_{2}$ equation for Japanese children aged 2 years or less. The results suggest that eGFR $_{\text {under } 2}$ equation could be a useful parameter.

Author contributions All authors contributed to the study conception and design. Material preparation, data collection and analysis were performed by YG, OU. The first draft of the manuscript was written by YG and all authors commented on previous versions of the manuscript. All authors read and approved the final manuscript.

\section{Declarations}

Conflict of interest The authors declare that no conflict of interest exists.

Human and animal rights All procedures involving human participants were in accordance with ethical standards of the institution at which the studies were conducted (approval number in Japanese Red Cross Aichi Medical Center Nagoya Daini Hospital: 1447S), and with standards of the 1964 Helsinki declaration and its later amendments or comparable ethical standards.

Informed consent Written informed consent was not obtained because of the use of retrospective data for clinical use. This information is available on the website (opt-out).

Open Access This article is licensed under a Creative Commons Attribution 4.0 International License, which permits use, sharing, adaptation, distribution and reproduction in any medium or format, as long as you give appropriate credit to the original author(s) and the source, provide a link to the Creative Commons licence, and indicate if changes were made. The images or other third party material in this article are included in the article's Creative Commons licence, unless indicated otherwise in a credit line to the material. If material is not included in the article's Creative Commons licence and your intended use is not permitted by statutory regulation or exceeds the permitted use, you will need to obtain permission directly from the copyright holder. To view a copy of this licence, visit http://creativecommons.org/licenses/by/4.0/.

\section{References}

1. Schwartz GJ, Muoz A, Schneider MF, Mak RH, Kaskel F, Warady BA, Furth SL. New equations to estimate GFR in children with CKD. J Am Soc Nephrol. 2009;20(3):629-37.

2. Uemura $\mathrm{O}$, Honda M, Matsuyama T, Ishikura K, Hataya $\mathrm{H}$, Nagai T, Ikezumi Y, Fujita N, Ito S, Iiijima K. Is the new Schwartz equation derived from serum creatinine and body length suitable for evaluation of renal function in Japanese children? Eur J Pediatr. 2012;171(9):1401-4.

3. Uemura O, Nagai T, Ishikura K, Ito S, Hataya H, Gotoh Y, Fujita N, Akioka Y, Kaneko T, Honda M. Creatinine-based equation to estimate the glomerular filtration rate in Japanese children and adolescents with chronic kidney disease. Clin Exp Nephrol. 2014;18(4):626-33.

4. Gotoh Y, Uemura O, Ishikura K, Sakai T, Hamasaki Y, Araki Y, Hamada R, Honda M. Validation of estimated glomerular 
filtration rate equations for Japanese children. Clin Exp Nephrol. 2018;22(4):931-7.

5. Uemura O, Ishikura K, Gotoh Y, Honda M. Creatinine-based estimated glomerular filtration rate for children younger than 2 years. Clin Exp Nephrol. 2018;22(2):483-4.

6. Nagai T, Uemura O, Ishikura K, Ito S, Hataya H, Gotoh Y, Fujita N, Akioka Y, Kaneko T, Honda M. Creatinine-based equations to estimate glomerular filtration rate in Japanese children aged between 2 and 11 years old with chronic kidney disease. Clin Exp Nephrol. 2013;17(6):877-81.

7. Uemura $\mathrm{O}$, Nagai $\mathrm{T}$, Ishikura $\mathrm{K}$, Ito $\mathrm{S}$, Hataya $\mathrm{H}$, Gotoh $\mathrm{Y}$, Fujita N, Akioka Y, Kaneko T, Honda M. Cystatin C-based equation for estimating glomerular filtration rate in Japanese children and adolescents. Clin Exp Nephrol. 2014;18(5):718-25.

8. Ikezumi Y, Uemura Y, Nagai T, Ishikura K, Ito S, Hataya H, Fujita $\mathrm{N}$, Akioka Y. Beta-2 microglobulin-based equation for estimating glomerular filtration rates in Japanese children and adolescents. Clin Exp Nephrol. 2015;19(3):450-7.

9. Uemura O, Honda M, Matsuyama T, Ishikura K, Hataya H, Yata N, Nagai T, Ikezumi Y, Fujita N, Ito S, Iijima K, Kitagawa T. Age, gender, and body length effects on reference serum creatinine levels determined by an enzymatic method in Japanese children: a multicenter study. Clin Exp Nephrol. 2011;15(5):694-9.

Publisher's Note Springer Nature remains neutral with regard to jurisdictional claims in published maps and institutional affiliations. 